\title{
BIOSSEGURANÇA NO ENSINO TÉCNICO: DE QUE MANEIRA OS ESTETICISTAS ASSOCIAM ESTE TEMA A PRÁTICA DE SUAS ATIVIDADES?
}

\author{
G. K. M. M. NERY ${ }^{1}$, J. F. NERY ${ }^{2}$ \\ Instituto Nacional do Semiárido \\ ORCID ID: https://orcid.org/0000-0003-3411-245X ${ }^{1}$ \\ gleydson.kleyton@gmail.com ${ }^{1}$
}

Submetido 17/05/2020 - Aceito 27/10/2020

DOI: 10.15628/holos.2020.10135

\section{RESUMO}

O técnico em estética tem como atribuição atender e cuidar de seus pacientes, apesar desta categoria não apresentar formação médica fica claro a necessidade do mínimo de certificação para o desenvolvimento dos procedimentos Desta forma, a disciplina de biossegurança tem grande relevância na prática estetica, uma vez que, visa tratar ações que contribuem para a segurança dos indivíduos, tratando da construção humana coletiva, levando em consideração o conjunto de práticas sociais e culturais no exercicio da função. Sendo assim, este estudo teve como objetivo identificar como os discentes do curso técnico em Estética identificam os conceitos e as práticas de biossegurança na sua atuação profissional. $\mathrm{O}$ trabalho foi realizado em uma faculdade particular com uma turma egressa do curso técnico em estética. O estudo caracterizou-se como descritivo, dividido em duas etapas: a percepção prévia e formalização dos conceitos. A análise dos dados foi realizada com base na avaliação do discurso individual e coletivo, por meio de grupos focais. Foi observado que os discentes egressos possuem conceitos sobre a temática, contudo apresentam muitas lacunas entre as informações e após a formalização dos conceitos observou-se que ainda há uma necessidade de valorização da disciplina, uma vez que, os discentes apresentam ainda um conhecimento muito superficial da disciplina e de sua influência na prática estética.

PALAVRAS-CHAVE: Estética, Segurança Profissional, Percepção.

\section{BIOSAFETY IN TECHNICAL EDUCATION: HOW DO ESTETICISTS ASSOCIATE THIS THEME WITH THE PRACTICE OF THEIR ACTIVITIES?}

\begin{abstract}
The aesthetics technician is responsible for caring for and caring for their patients, although this category does not have medical training, it is clear the need for minimum certification for the development of procedures. Thus, the discipline of biosafety has great relevance in aesthetic practice, once which aims to address actions that contribute to the safety of individuals, dealing with collective human construction, taking into account the set of social and cultural practices in the exercise of the function. Thus, this study aimed to identify how the students of the technical course in Aesthetics identify the concepts and practices of biosafety in their professional performance. The work was carried out in a private
\end{abstract}

college with a group that graduated from the technical course in aesthetics. The study was characterized as descriptive, divided into two stages: prior perception and formalization of concepts. Data analysis was performed based on the assessment of individual and collective discourse, through focus groups. It was observed that the graduating students have concepts about the theme, however they present many gaps between the information and after the formalization of the concepts it was observed that there is still a need for valuing the discipline, since the students still have a very superficial knowledge of the discipline and its influence on aesthetic practice.

KEYWORDS: Aesthetics, Professional Security, Perception. 


\section{INTRODUÇÃO}

A educação técnica profissionalizante não consiste apenas na utilização do conhecimento para execução de atividades, uma vez que requer além do domínio operacional a compreensão holística do processo produtivo, com a compreensão do saber tecnológico que informa a execução pessoal e a valorização cultural da profissão pela mobilização dos valores éticos nas tomadas de decisões (Cordão, 2002).

O técnico em estética de acordo com CIDESCO (Comitê Internacional de Estética e Cosmetologia), tem como atribuição atender e cuidar de seus clientes/pacientes com base na formação técnica adequada e total domínio de todos os setores que compões a estética e a cosmetologia (Patti, 2009). Apesar desta categoria não apresentar formação médica fica claro que para o exercicio há necessidade de licença e o mínimo de certificação em cursos para o desenvolvimento dos procedimentos faciais e corporais (D’Angelo, 2010).

A disciplina de biossegurança visa tratar ações que contribuem para a segurança dos indivíduos, independente da área de atuação, pois trata da construção humana coletiva, levando em consideração o conjunto de práticas sociais e culturais, próprios da comunidade a qual pertence o grupo social (Costa; Costa, 2007). No Brasil, a biossegurança possui duas correntes: (i) a legal, que trata assuntos envolvendo a manipulação de DNA e pesquisas com células embrionárias - Lei de Biossegurança no 11.105/2005; e (ii) a praticada, principalmente relativa a instituições de saúde, que envolve riscos químicos, físicos, biológicos, ergonômicos e psicossociais no contexto da segurança ocupacional (Costa, 2000).

Entre os conceitos fomentados ao longo dos cursos da área de saúde, o que inclui a estética, a biossegurança se destaca como um dos conteúdos que apresentam uma aprendizagem defasada e fragmentadas, sem uma visão holística, não construindo assim uma rede de conceitos aplicáveis a realidade dos discentes (Kirchner, 2013). Deste modo, esta falta de qualificação tem proporcionado sérias consequências a prática estética, uma vez que, além do desconhecimento de conceitos básicos sobre as atividades e as medidas de segurança que prezam pelo equilíbrio entre o profissional, cliente e o ambiente dos procedimentos estético, muito se tem discutido em relação a susceptibilidade destes ambientes na veiculação e contaminação por microrganismos (Johnson et al., 2001; Oliveira; Focaccia, 2010).

Devido a inerente necessidade de identificar que no local de trabalho e/ou convivência podemos apresentar diversos riscos à saúde, interferindo diretamente na qualidade de vida e na biossegurança das relações ali estabelecidas, este estudo teve como objetivo identificar como os discentes do curso técnico em Estética identificam os conceitos e as práticas de biossegurança na sua atuação profissional. 


\section{METODOLOGIA}

\subsection{Caracterização e delineamento do estudo}

O trabalho foi desenvolvido com uma turma egressa do curso técnico em Estética Facial e Corporal de uma faculdade particular localizada na região central do município de Campina Grande (PB) no período de outubro a novembro de 2018, com a participação de 27 alunos.

Após a aprovação da direção da faculdade, a pesquisa foi desenvolvida durante as aulas da disciplina de Biossegurança aplicada a Estética. Todas atividades realizadas obedecerem aos requisitos básicos da Resolução 466/12 do Conselho Nacional de Saúde, Ministério da Saúde do Brasil, onde para a participação na pesquisa os discentes foram previamente esclarecidos quanto a pesquisa, seus objetivos, possibilidade de participação e advertindo-os dos possíveis riscos, fins lucrativos ou divulgação de imagem.

O estudo caracterizou-se como descritivo abordando aspectos qualitativos, o qual concentra-se em explorar e descrever a qualidade do vínculo estabelecido entre as ações empreendidas no evento e no problema em investigação no intuito de compreender o significado que os participantes atribuem as experiências vivenciadas. (Motta-Roth; Hendges, 2010).

Na primeira etapa do estudo foi realizada a coleta de dados conduzida através da aplicação de um formulário estruturado sobre tópicos de biossegurança na Estética, que considerava as seguintes variáveis: (i) definição de biossegurança; (ii) tipos de riscos na prática estética, (iii) práticas de limpeza e higienização, (iv) gerenciamento de resíduos e (v) analise estrutural do estabelecimento, com objetivo de avaliar o conhecimento prévio do aluno sobre a temática.

$\mathrm{Na}$ segunda etapa elaborou-se uma atividade baseada na técnica "brainstorming", em português conhecida como tempestade de ideias, metodologia essa que objetiva ampliar as visões do discentes sobre determinado conteúdo, proporcionando que enxerguem relações entre o conteúdo estudado e o seu cotidiano (Nicoletti; Sepel, 2015). Como atividade baseada na técnica de "brainstorming", objetivou-se a coleta de dados pela esquematização de mapas de risco de estabelecimentos, pré-definidos pelo docente, onde podemos identificar a concepção dos conceitos estudados na prática simulada em um ambiente estético. Servindo como pós-teste, uma vez que, foi realizado na finalização da disciplina.

\subsection{Análise dos Dados}

Para análise e discussão dos resultados obtidos, o estudo utilizou análise conteúdo (Bardin, 2011), através das respostas dos formulários e recortes das falas dos discentes durantes as atividades desenvolvidas. As concepções prévias dos discentes foram analisadas individualmente, no intuito de identificar a proximidade dos profissionais a serem formados com a segurança no ambiente estético. A análise das falas durante a segunda etapa do estudo foi analisada de forma coletiva, a partir da construção de grupos focais como proposto por Trad (2009).

As percepções foram analisadas inicialmente em uma perspectiva de identificação de conceitos sobre os riscos na prática profissional e as práticas de segurança na atuação profissional 
e em um segundo momento analisou-se as ideias construídas a partir da atividade realizada que envolvem a descrição e compreensão da influência da biossegurança na atuação bem como no ambiente estético.

Para análise dos mapas de risco, o método implicou na criticidade das informações do funcionamento de estabelecimentos estético como equipamentos, instalações, materiais, produtos, fluxos, resíduos, turnos de trabalho e atividades dos trabalhadores e seguiu-se a representação gráfica dos riscos ambientais utilizando-se círculos de tamanhos proporcionais à gravidade - grande, médio e pequeno, segundo a classificação de riscos contida na NR-5: físicos (verde), químicos (vermelho), biológicos (caramelo/marrom), ergonômicos (amarelo) e de acidentes (preto) (Mattos; Queiroz, 2002).

\section{RESULTADOS E DISCUSSÃO}

\subsection{Percepção inicial dos conceitos e práticas}

Previamente, observou-se que os discentes detinham conhecimento sobre a disciplina. Contudo, ao exporem seus conhecimentos sobre a biossegurança, foi possível identificar há lacunas no que se refere aos termos básicos, a execução das práticas de segurança e o gerenciamento dos riscos no local de trabalho (Figura 1). Uma vez que, biossegurança compreende ações destinadas na prevenção, redução, controle ou eliminação de riscos relacionados as atividades que possam interferir na saúde humana assim como animal e do ambiente (ANVISA, 2009).

Ainda segundo Kirchner (2013), identifica-se ainda um nível de desconhecimento dos profissionais da saúde sobre esta temática, o que evidencia a necessidade de implantação de metodologias que valorizem a qualidade de vida e conscientização dos profissionais por meio de educação continuada.

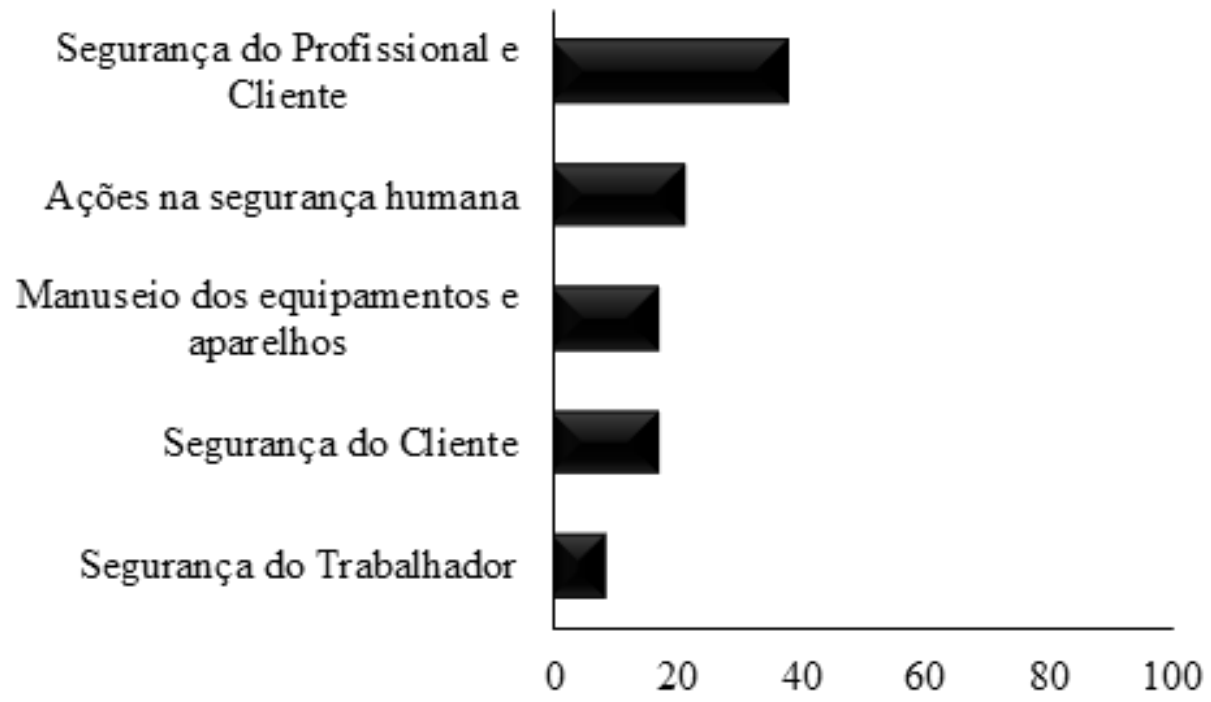

Figura 1: Categorização das percepções dos discentes sobre a temática biossegurança. 
$\mathrm{Na}$ identificação de risco, observou-se que a maior parte interpreta o risco como uma condição de risco direta a saúde, ou seja, um acidente ou ferimento causado imediato (54\%), outra percepção de risco relacionado a estética é o uso inadequado de aparelhos e produtos (25\%) e outra parcela não apresenta uma interpretação clara do risco, identificando-o como uma situação de perigo (21\%). O conceito de risco e perigo são termos muito utilizados dentro da biossegurança, contudo o risco indica uma situação na qual se consegue medir o perigo através do conhecimento dos acontecimentos, ou seja, aquele o qual tem-se como prevenir e devendo sempre ser realizado, enquanto que, o perigo é aquele que existe quando não se há conhecimento dos acontecimentos, ou seja, aquele que é desconhecido ou não conhecemos bem (Sanders \& McCormick, 1993).

Nas possíveis justificativas que causam riscos durante as atividades estéticas obteve-se as seguinte categorias (i) desqualificação profissional, (ii) falta de estrutura física, (iii) risco biológico, (iv) risco físico, (v) não utilização de EPI's (Equipamento de Proteção Individual) e a (vi) utilização de produtos e procedimentos inadequados (Tabela 1). Todos os riscos citados pelos entrevistados tiveram base lógica no exercício da função no meio estético. Observou-se também que, 90\% das informações cedidas decorriam não só do conhecimento prévio dos discentes, mas também de suas experiências ao frequentar tais locais para realização de algum procedimento.

Os riscos no ambiente estético encontram-se associados à não formação ou formação deficitária destes profissionais, segundo Garbaccio e Oliveira (2012), observa-se baixo nível educacional associado a pouca capacitação técnica, tendo um percentual de 12,3 a 56,7\% com escolaridade básica (ensino médio completo) sem formação técnica e apenas um percentual entre 19\% a 40\% com qualificação técnica para exercer as atividades estéticas.

Atrelado a uma formação deficiente, outros riscos como a não utilização de equipamentos de proteção individual (EPI's) tem se tornado cada vez mais frequente, submetendo assim não só o profissional como também o próprio cliente a diversos riscos. Além disto, estima-se que a utilização de EPI's, como luvas, ocorra de forma inapropriada não havendo substituição após a realização de procedimento entre os clientes possibilitando assim maior possibilidade de contaminação pelo contato com líquidos corporais, sangue, pele não íntegra e mucosas entre clientes e com o próprio profissional (ANVISA, 2011; Silva et al., 2017).

Tabela 1: Categorização dos riscos percebidos pelos discente no exercício de esteticista e discursos relativos

\begin{tabular}{c|l}
\hline RISCOS & \multicolumn{1}{c}{ DISCURSOS } \\
\hline \multirow{3}{*}{ Desqualificação Profissional } & "Não conhecer bem os procedimentos, aparelhos e produtos" \\
Falta de Estrutura Física & "O risco de algum procedimento errado, ou seja, algum tratamento \\
& inadequado para ele (paciente), comprometendo assim sua saúde" \\
& (E03) \\
"Local inadequado" (E06) & "[...] falta de limpeza do ambiente." (E08) \\
Risco Biológico & "[...] podem ser por meio de doenças de pele ou contato direto com \\
& o sangue assim como secreções purulentas." (E15)
\end{tabular}


Risco Físico

Não Utilização de EPI's

Utilização de Produtos Inadequados
"Alguns riscos como o de queimaduras [...] (E08)

"[...] reutilização de materiais individuais e/ou não utilização dos EPI's." (E24)

"Produtos utilizados de forma inadequada, pessoas com tipos de patologias e não informa ao profissional [...]" (E12) "[....] fiscalização dos produtos e aparelhos." (E01)

Como forma de prevenção aos riscos durante as atividades estéticas, solicitou-se aos discentes que descrevessem as possíveis práticas de segurança que poderiam ser utilizadas antes ou durantes a execução das atividades (Figura 2). Entre as práticas mais citadas foi possível observar a persistência com a preocupação em relação a qualificação para realização das atividades estéticas e o uso da ficha de avaliação/anamnese, onde o esteticista previamente a realiza no intuito de indicar o procedimento adequado de acordo com as características morfológica ou fisiológicas do cliente (FEBRAPE, 2003). Outra, alternativa foi a de higienização e a limpeza do ambiente, uma vez que, configura um processo obrigatório, correspondendo a limpeza diária do ambiente e dos equipamentos de trabalho tornando assim a condição ideal de trabalho reduzindo a contaminação e proliferação de microrganismos causadores de patologias (ANVISA, 2009; Moraes et al., 2012).

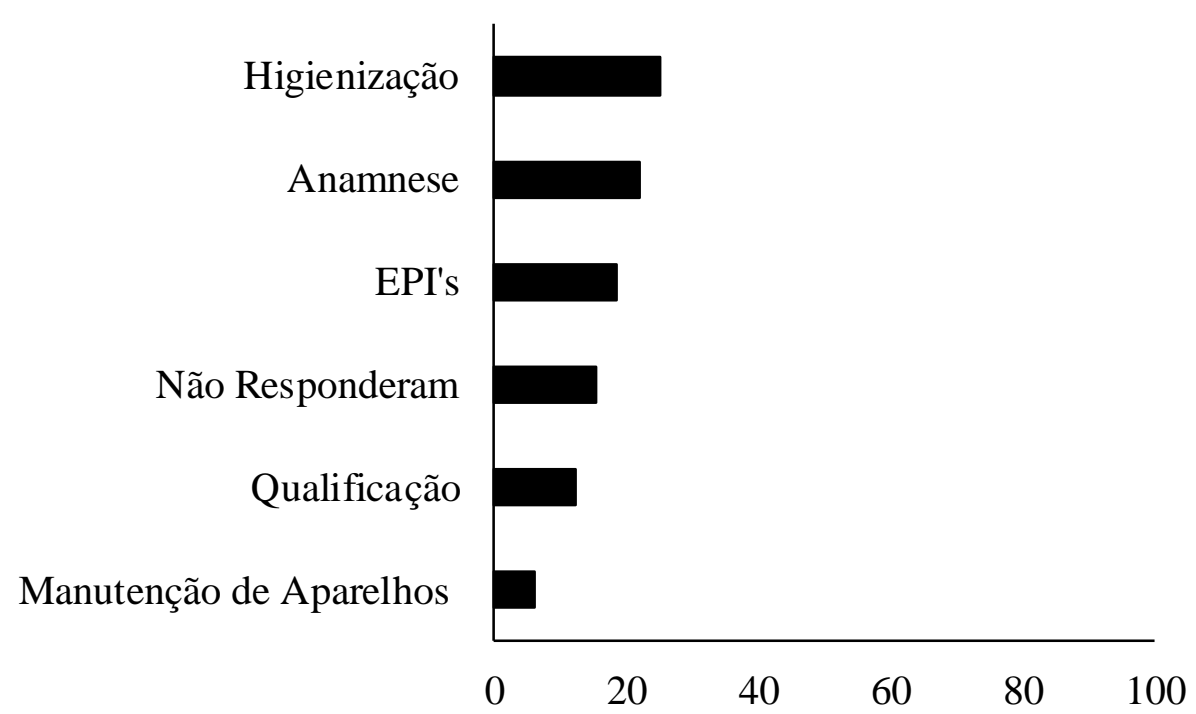

Figura 2: Principais práticas para minimização de riscos associados a atividade estética.

Utilizando-se desta percepção sobre práticas de limpeza e higienização, solicitou-se aos discentes que definissem o que caracteriza e como poderiam ser as práticas de limpeza e higienização a serem utilizados pelos profissionais da estética. Apesar do conjunto de resposta conseguirem identificar diversas medidas de higienização, prevaleceu-se práticas de limpeza e higienização superficiais (64\%), com a retirada apenas de sujidades, sendo considerado suficiente pelos discentes estas medidas para tornar seguro o ambiente e equipamentos (Figura 3). 
Contudo a higienização adequada consiste em diferentes processo: (i) limpeza, refere-se a retirada de sujidades de qualquer superfície, geralmente associada a limpeza do ambiente; (ii) desinfeç̧ão, refere-se a eliminação da maior parte de microrganismos patogênicos, com exceção das forma de resistência (esporos), geralmente utilizado na higienização de equipamentos que não tem contato com fluidos corporais e superfícies de contato direto com profissional ou cliente; e (iii) esterilização, corresponde a retirada de todos os microrganismos incluindo as formas de resistência (esporos), utilizado para equipamentos perfurocortantes reutilizáveis (ANVISA, 2009).

Entre as citações nota-se que apenas $4 \%(n=1)$ tem a concepção de higienização adequada para equipamentos perfurocortantes, enquanto os demais reconhecem apenas os métodos de higienização: limpeza e desinfecção.

\section{Esterilização:}

"[...] equipamentos que tenham contato direto com os clientes devem-se fazer a esterilização." (E15)

\section{Desinfecção:}

"Prática de desinfecção a partir do uso de álcool para higienizar as macas, aparelhos e os próprios pacientes" (E11)

\section{Limpeza:}

"Limpeza do ambiente, dos aparelhos, uso de materiais descartáveis e cuidado no manuseio de produtos utilizando espátulas." (E09)

Observou-se que apenas $12,5 \%$ dos discentes identificaram a utilização de algum produto entre o processo de higienização, sempre relacionando com o processo de desinfecção de aparelhos para eliminação de microrganismos. Contudo, para total eliminação dos microrganismos patogênicos os instrumentos (termorresistentes) devem passar pelo processo de esterilização. No processo de esterilização torna-se obrigatório o armazenamento dos artigos em invólucros adequados, ou seja, limpos e protegidos (ANVISA, 2009).

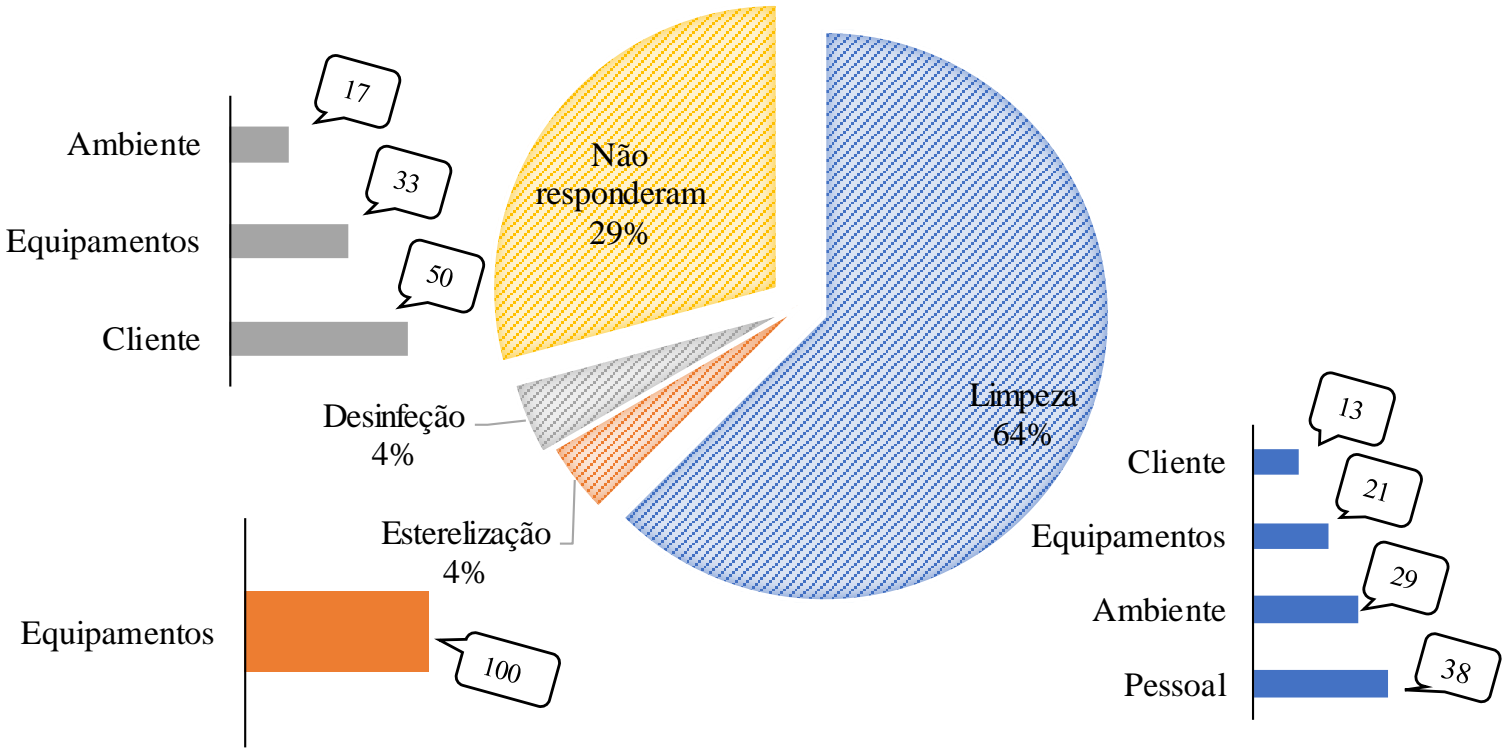

Figura 3: Categorização das práticas de higienização conhecidas pelos discentes e forma de utilização. 
Sobre a destinação dos resíduos gerados pelos estabelecimentos, foi possível observar que 90\% dos discentes não identificaram a necessidade de um descarte específico para o material gerado por centros estéticos sendo descartado junto com resíduo comum, contudo, materiais que apresentam contato direto com fluidos corporais necessitam de descarte apropriado não podendo ser descartado diretamente no lixo comum. Há um regulamento de gerenciamento de resíduos de serviços de saúde que devem ser seguidos por estabelecimentos que levem risco à saúde, que compreende as etapas intra e extra estabelecimento, como separação, armazenamento, transporte e destino final (tratamento do resíduo), visando à proteção do homem e do meio ambiente (Mello, 2011).

\subsection{Avaliação dos conhecimentos formalizados}

No intuito de avaliar a construção dos conhecimentos durante a disciplina de biossegurança, optou-se pela elaboração de mapa de risco em diferentes estabelecimentos estéticos, identificando assim a caracterização de um ambiente estético adequado as práticas sugeridas, além de identificar também os principais riscos e os respectivos graus (Figura 4). Os ambientes estéticos propostos foram (i) esmaltaria, (ii) salão de beleza, (iii) centro de depilação e (iv) centro estético.
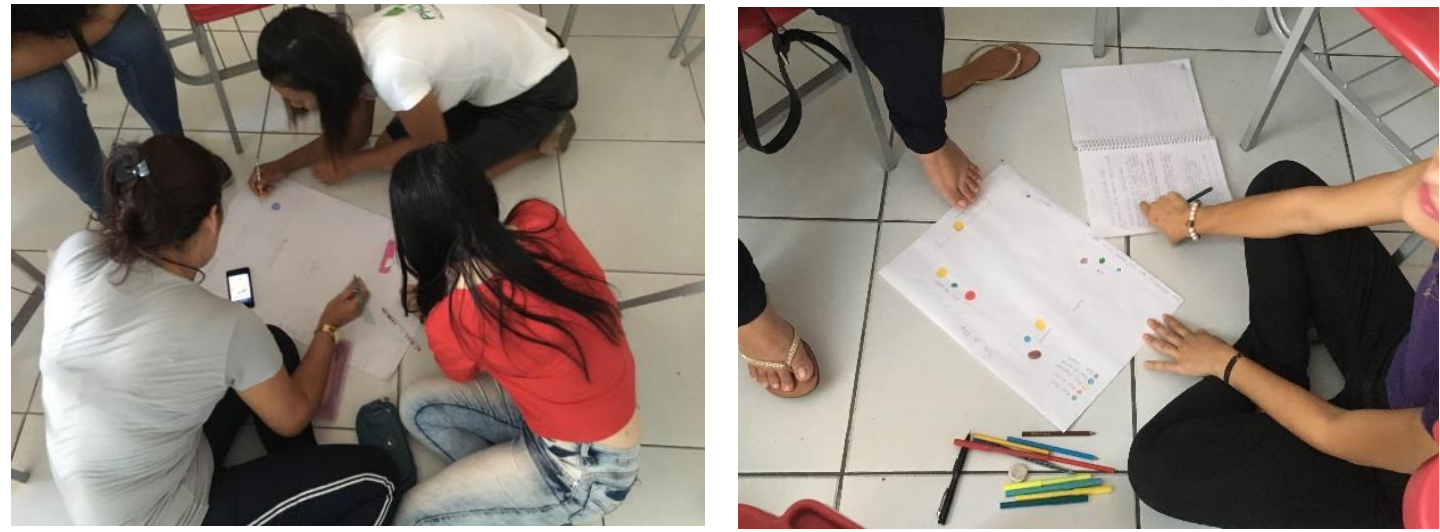

Figura 4: Socialização e confecção dos mapas de risco com os discentes do curso de Estética (Fonte: Autor).

Foi possível observar que entre os grupos todos representaram os riscos biológicos e ergonômicos como os de maiores incidência nos ambientes estéticos, isto decorre do fato que, as práticas estéticas condizem em atividades diretas com o corpo do cliente que promove uma maior facilidade na promoção de contaminação com doenças, assim como também são atividades que apresentarem movimentos repetitivos e desgastantes possibilitando as conhecidas Lesões por esforço repetitivo (LER) e Doenças osteomusculares relacionadas ao trabalho (DORT).

Em relação a estrutura física dos ambientes observou-se que todos os mapas apresentaram a compartimentalização das áreas de trabalho como uma medida de redução de riscos, a exemplo do mapa do salão de beleza, que representaram áreas distintas para realização de procedimentos capilares, onde há maior percentual de risco, representado por todos os tipos biológicos, químicos, físicos, ergonômicos e acidentes, da área de lavagem e manicure que apresentam menor incidência de risco (Figura 5). 
Observa-se que a predominância dos riscos além de ocorrem nos locais de atendimentos como as cabines, área de lavagem, depilação ou escovaria também são bem caracterizados quanto ao tipo e incidência em ambientes de alimentação (cozinha ou copa), recepção e banheiros (W.C), o que demostra a formalização dos conceitos no qual ambientes comuns de susceptibilidade, grande fluxo de pessoas e de contato com fluidos corporais apresentam risco significativo de precaução.
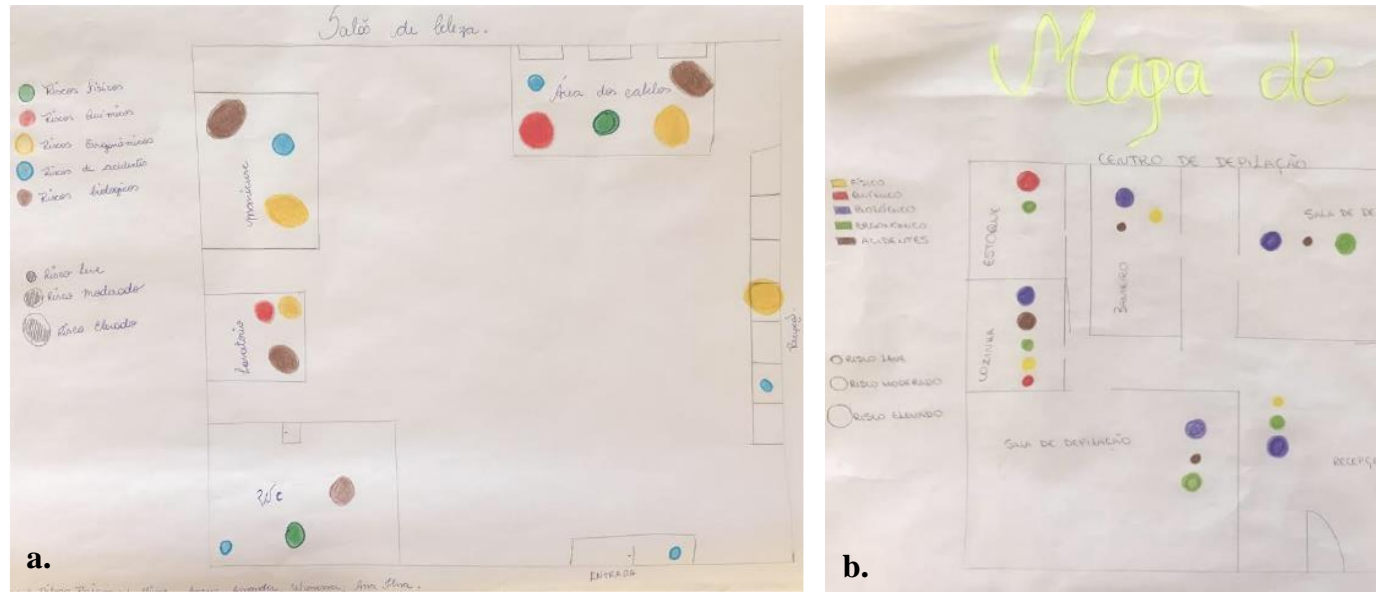

b.
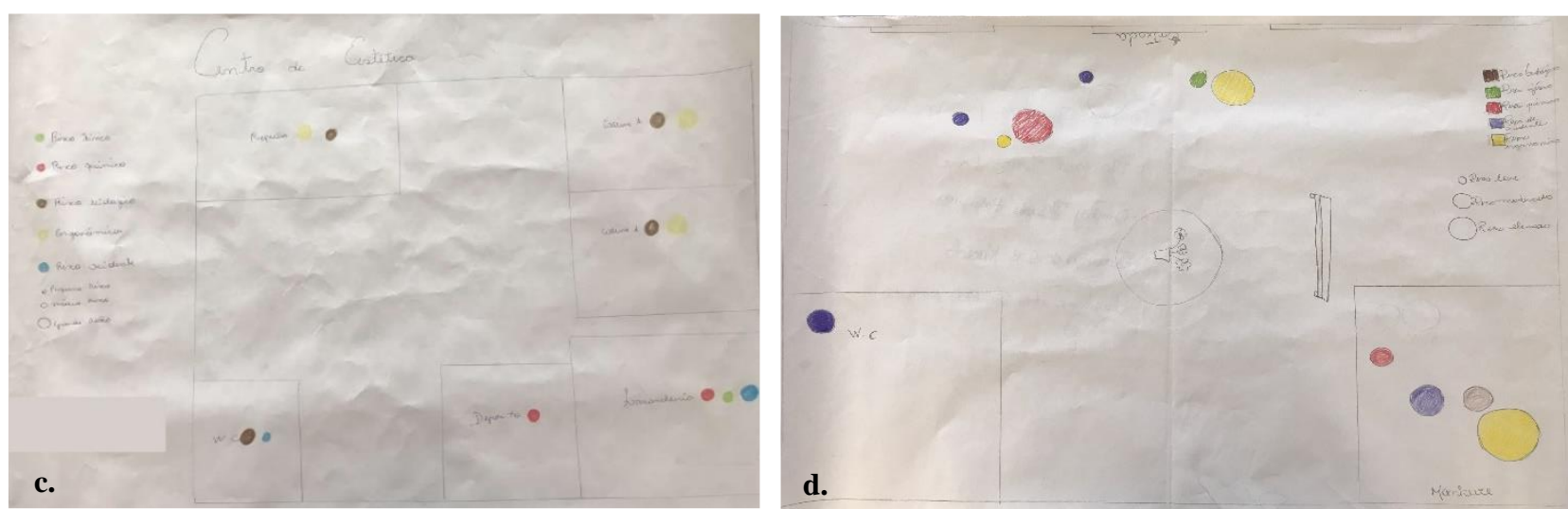

Figura 5: Mapa de risco dos diferentes tipos de ambiente estéticos descrevendo os principais riscos e o grau de incidências.: a. salão de beleza, b. centro de depilação, c. centro estético e d. esmaltaria (Fonte: Autor).

Contudo, a determinação de áreas de esterilização, como medidas de emergência foram esquecidas ou mal sinalizadas nos mapas sugeridos, o que preocupa por serem práticas que devem ser adotas para qualquer ambiente que seja alvo de circulação de um determinado contingente populacional evitando assim uma maior possibilidade de contaminação ou riscos associados, o que geralmente não ocorre em ambientes estéticos (França et al., 2017).

Durante a construção dos mapas e a discussão em sua elaboração, foi possível observar que muitas das afirmações para melhorias da estrutura do ambiente estético estavam contidos não apenas nas informações cedidas durantes a disciplina, mas também pela vivência ao frequentar estes estabelecimentos como clientes. Dessa forma, nos discursos, outras práticas de segurança foram sugeridas, apesar de não constarem na elaboração do mapa, como a disponibilização de álcool em gel para higienização das mãos dos funcionários e clientes e a utilização de materiais descartáveis como toalhas, palitos de unha, esponjas de aplicação de maquiagem, espátulas para 
utilização em depilação, evitando assim a necessidade de sala voltadas para esterilização de materiais.

\section{CONCLUSÃO}

A formação técnica e profissionalizante dos discentes em estética apresentou-se carentes da contextualização com a atuação profissional, o que reflete um processo de ensino aprendizagem distante de uma educação significativa. Portanto, a utilização de métodos que promovam a sensibilização da importância de conceitos teóricos que estabelecem a segurança do trabalho no cumprimento da atividade profissional torna-se essencial. As normas de biossegurança como a utilização de EPI's, processo de higienização adequados e o estabelecimento de um espaço adequado para a atividade profissional promovem um ambiente seguro.

Dessa forma, identifica-se a importância da construção do conhecimento voltado para melhoria nas práticas de segurança, assim como a inserção de metodologias que visem um diferencial ao proporcionar dinamicidade e melhor compreensão com vivências práticas, correlacionando a teoria com o cotidiano, uma vez que, a partir delas que se proporciona a visualização do funcionamento e responsabilidade das atividades a serem exercidas na profissão, ainda mais quando retratamos o universo estético que ainda passa por processo de regulamentação.

\section{REFERÊNCIAS BIBLIOGRÁFICAS}

ANVISA. (2009). Referência técnica para o funcionamento dos serviços de estética e embelezamento sem responsabilidade médica. Brasília-DF.

BARDIN, L. (2011). Análise de conteúdo. São Paulo: Edições.

Cordão, F. A. (2002). A LDB e a nova educação profissional. Revista de Educação Profissional, 28 (1).

Costa, M.A.F. (2000). Qualidade em Biossegurança. Rio de Janeiro: Qualitymark.

Costa, N. (2007). Aspectos Ergonômicos, Posturais e o trabalhador da área de saúde. Semina: Ciências Biológicas e Saúde, 28(2), 109-118.

D’ANGELO, J. M. (2010). Estratégias de negócios para salões de beleza e spas; São Paulo: Cengage Learning.

França, S. R. D; Alencar, E. A.; Bacelar, S. A.; Rodrigues, L. N.; Nascimento, A. L. A.; Ferreira, P. R.; Carvalho, S. T. R. F. (2017). Percepção de clientes em relação às normas de biossegurança utilizadas nos centros de embelezamento e estética. Revista Ceuma Perspectivas, 30(2), 101 114.

FEBRAPE. Federação Brasileira de Profissionais Esteticistas. (2003) Código de Ética dos Esteticistas Brasileiros. 
Garbaccio, J. L.; Oliveira, A. C. (2012). Biossegurança e risco ocupacional: revisão integrativa. Revista Eletrônica de Enfermagem, 14(3), 702 - 711.

Johnson, I. L.; Dwyer, J. J. M.; Rusen, I. D.; Shahin, R.; Yaffe, B. (2001). Survey of Infection Control Procedures at Manicure and Pedicure Establishments in North York. Can J Public Health, 92(2), 134-137.

Kirchner, R. M.; Loebens, L.; Scherer, M. E.; Ochôa, P. O.; Chaves, M. A.; Silinske, J.; Soares, A. R. (2013). Estratégias para a biossegurança e minimização dos riscos de agravos à saúde em laboratórios de um centro universitário. Revista Eletrônica em Gestão, Educação e Tecnologia Ambiental, 14(14), 2855- 2861.

Mattos, U. A. O.; Queiroz, A. R. (2002). Mapa de risco. In: Teixeira P, Valle S, (Eds.), Biossegurança. Uma abordagem multidisciplinar (p. 111-122). Rio de Janeiro: Fiocruz.

Mello, J. (2011). Biossegurança e Estética. Revista Científica INA, 3(3), p. 5 - 45.

Moraes, J. T.; Barbosa, F. I.; Costa, T. R. S.; Ferreira, A. F. (2012). Hepatite B: percepção dos riscos e adoção de medidas de biossegurança por manicures/pedicures de Itaúna-MG. Revista Enferm Cent O Min, 2(3), 347-357.

Motta-Roth, D.; Hendges, G. R. (2010). Produção textual na universidade. Revista Linguagem \& Ensino, 16(1), 263-267.

Nicoletti, E. R.; Sepel, L. M. N. (2015). Organização inicial de uma Ilha Interdisciplinar de Racionalidade a partir de um tema específico da biologia. Ciência e Natura, 37(3), 808-820.

Oliveira, C. L. (2006). Significado e contribuições da afetividade, no contexto da Metodologia de Projetos, na Educação Básica. (Dissertação de mestrado defendida no Programa de PósGraduação em Educação Tecnológica do Centro Federal de Educação Tecnológica de Minas Gerais, Belo Horizonte-MG). Recuperado de: http://www.tecnologiadeprojetos.com.br/banco objetos/\%7B23B2621B-995B-4F97-B5C6180A42FDBD14\%7D Projeto\%20de\%20Pesquisa\%20de\%20Mestrado\%20\%20Cacilda\%20\%2 OVers\%C3\%A30\%20Final\%206\%20pdf.pdf

Oliveira, A. C. D. S.; Focaccia, R. (2010). Survey of hepatitis B and C infection control: procedures at manicure and pedicure facilities in São Paulo, Brazil. Braz J Infect Dis., 14(5), 502-507.

PIATTI, I. L. (2009). Ética na Estética: respeito ao cliente e sucesso para o profissional. Nova Vida Estética, 7, 41-43.

Sanders, M. S.; McCormick, E. J. (1993) Human Error, Accidents, and Safety. In: Sanders, M. S.; McCormick, E. J. (Eds.). Human Factors in Engineering and Design (pp. 655-695). New York: McGraw-Hill.

Silva, A. S.; Valiatti, T. B.; Barcelos, I. B.; Martins, R. C.; Oliveira, D. F.; Castro, B. S. (2017). Verificação da prática de biossegurança por manicures/pedicuros em salões de beleza localizados no município de Ji-Paraná/RO. Revista Interdisciplinar de Estudos em Saúde, 6(1), 39-49. 
Trad, L. A. B. (2009). Grupos focais: Conceitos, procedimentos e reflexões baseadas em experiências com o uso da técnica em pesquisas de saúde. Revista de Saúde Coletiva, 19 (3), 777-796.

\section{COMO CITAR ESTE ARTIGO:}

Nery, G. K. M. M., Nery, J. F. (2020). Biossegurança no ensino técnico: de que maneira os esteticistas associam este tema a prática de suas atividades? Holos. 36(6), 1-12.

\section{SOBRE OS AUTORES}

G. K. M. M. NERY

Biólogo, Especialista em Etnobiologia e Mestre em Ecologia e Conservação - Universidade Estadual da Paraíba (UEPB). Pesquisador do Núcleo de Recursos Hídricos - Instituto Nacional do Semiárido (INSA). Email: gleydson.kleyton@gmail.com

ORCID ID: https://orcid.org/0000-0003-3411-245X

\section{J. F. NERY}

Bióloga, Universidade Estadual da Paraíba (UEPB); Mestre em Desenvolvimento e Meio Ambiente, Universidade Federal da Paraíba (UFPB) e Doutora em Ecologia de Ecossistemas Aquáticos, Universidade Estadual de Maringá (UEM). Pesquisador do Núcleo de Recursos Hídricos - Instituto Nacional do Semiárido (INSA). E-mail: janiele.nery@insa.gov.br

ORCID ID: https://orcid.org/0000-0002-9720-6480

Editor(a) Responsável: Francinaide de Lima Silva Nascimento Pareceristas Ad Hoc: FÁBIO PORTELLA CORRÊA DE OLIVEIRA E KARLA NAYALLE OLIVEIRA

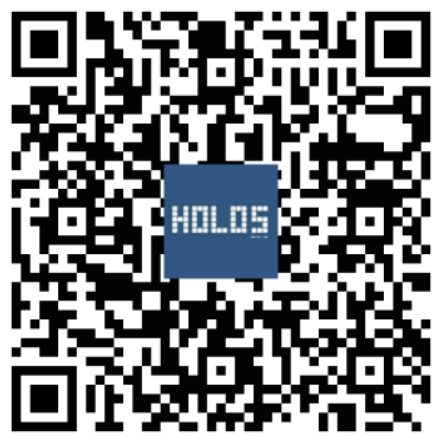

